\title{
Evaluasi Bangunan Pelindung Pantai Sisi Miring Dalam Upaya Penanggulangan Abrasi Pesisir Pantai
}

\author{
Akmal $^{1}$, Sahri Putra ${ }^{2}$ \\ Prodi Teknik Sipil, FakultasTeknikUniversitasMuhammadiyah Aceh, \\ 12akmal@unmuha.ac.id, ²Sahryputra83@gmail.com
}

\begin{abstract}
Abstrak
The coast of Kampung Jawa Lama, Banda Sakti Sub-district, Lhokseumawe City is a fishing area and densely populated. The breakwater building in the coastal area of Kampung Jawa Lama is a sloping Breakwater with a height of $1.5 \mathrm{~m}$ and a width of $1 \mathrm{~m}$. The type of breakwater used is usually determinet by the availability of material on the site. The problem in this research was the cause of abrasion and its impact, as well as how to plant coastal protection structures. The purpose of this study was to reduce the impact of erosion, abrasion and damage to the buildings and to re-evaluate coastal structures. The method used on this research is Hudson method and descriptive analysis by making direct observation and reviuwing research that has been done previously. The cause of abrasion is triggered by several factors such us tides, high sea waves and ocean currents that have the potential to cause damage as a result of strong winds that produce destructive waves. The community also receiver the impact of the abrasion, namely decreasing income, the place where they live is inundated by sea water and it affects the decline in the quality of life of the community. One of the efforts that can be applied to reduce the abrasion problem in the area is to build a Breakwater construction. Based on calculation, the results obtained in the planning reviuw of the existing shoreline protection building were $1.5 \mathrm{~m}$, so that to prevent abrasion the increase in height of the building $4.074 \mathrm{~m}$ was $5.574 \mathrm{~m}$ with a peak width of $1 \mathrm{~m}$ so that increase of $0.20 \mathrm{~m}$ was $1.2 \mathrm{~m}$, the thickness of the first layer of protection was $1.2 \mathrm{~m}$ and the thickness of the second layer was $0.60 \mathrm{~m}$. The width of the leg guard is $1.8 \mathrm{~m}$ with a thickness of $0.5 \mathrm{~m}$
\end{abstract}

Kata kunci: OHSM, Building Project, Construction.

\begin{abstract}
Abstrak
Pesisir Pantai Kampung Jawa Lama merupakan daerah nelayan dan padat penduduk. Bangunan pemecah gelombang pada daerah pesisir adalah breakwater sisi miring dengan tinggi 1,5 m dan lebar $1 \mathrm{~m}$. Tipe pemecah gelombang yang digunakan biasanya ditentukan oleh ketersediaan material pada tempat lokasi.Permasalahan dalam penelitian ini apakah penyebab terjadinya abrasi dan dampak yang ditimbulkan, serta bagaimana perencanaan bangunan pelindung pantai. Tujuan penelitian ini yaitu untuk mengevaluasi bangunan pelindung pantai dan mengurangi dampak erosi dan abras. di pesisir Pantai Kampung Jawa Lama pada saat gelombang ekstrim terjadi, air laut dapat terhempas kedaratan sampai ke perumahan warga hingga terjadi banjir rob. Upaya yang dapat diterapkan untuk mengurangi permasalahan abrasi di wilayah tersebut adalah dengan membangun konstruksi breakwater.Metode yang digunakan dalam penelitian ini adalah Metode Hudson. Penyebab abrasi dipicu oleh beberapa faktor seperti pasang surut, arus dan angin yang kencang sehingga menghasilkan gelombang yang merusak. Masyarakat juga menerima dampak abrasi tersebut yaitu pendapatan menurun, tempat tinggal tergenang oleh air laut dan mempengaruhi penurunan kualitas hidup. Berdasarkan perhitungan, hasil yang didapat pada bangunan sebelumnya adalah 1,5 $\mathrm{m}$, sehingga untuk mencegah abrasi pertambahan tinggi bangunan 4,074 $\mathrm{m}$ adalah 5,574 $\mathrm{m}$ dengan lebar puncak yang ada $1 \mathrm{~m}$ sehingga pertambahan 0,20 $\mathrm{m}$ adalah 1,2 m, tebal lapis lindung pertama 1,2 m dan tebal lapis lindung kedua 0,60 m. Lebar pelindung kaki 1,8 m dengan ketebalan 0,5 m
\end{abstract}

Kata kunci: Abrasi, breakwater sisi miring, pantai.

\section{Pendahuluan}

Pesisir pantai Kampung Jawa Lama merupakan salah satu daerah yang terancam masalah abrasi pantai. Abrasi pantai dapat menimbulkan kerugian yang sangat besar https://doi.org/10.37598/tameh.v10i1.129 dengan rusaknya kawasan pemukiman dan fasilitas-fasilitas yang ada di daerah tersebut. Untuk menanggulangi abrasi pantai langkah pertama yang harus dilakukan adalah mencari penyebab terjadinya abrasi. Dengan mengetahui penyebabnya, selanjutnya dapat 
ditentukan cara penanggulangannya, yaitu dengan membuat bangunan pelindung pantai atau meninjau ulang kembali bangunan pelindung pantai tersebut dengan menambah suplai sedimen batuan

Bangunan pelindung pantai saat ini adalah breakwater sisi miring dengan tinggi sekitar 1,5 meter dari jalan, bagian atas breakwater memiliki lebar sekitar 1 meter. Tetapi, di pesisir Pantai Kampung Jawa Lama pada saat gelombang ekstrim terjadi run up sampai ke perumahan warga hingga terjadi banjir rob.

Berdasarkan latar belakang yang telah diuraikan diatas, dapat diambil beberapa permasalahan pada penelitian ini yaitu, apa penyebab terjadinya abrasi pantai dan dampak yang ditimbulkan, serta bagaimana perencanaan bangunan pelindung pantai di Gampong Jawa Lama, Kota Lhokseumawe yang sesuai untuk melindungi dari abrasi. Tujuan penelitian ini yaitu untuk mengevaluasi bangunan pelindung pantai dan mengurangi dampak erosi dan abras. di pesisir Pantai Kampung Jawa Lama pada saat gelombang ekstrim terjadi, air laut dapat terhempas ke daratan sampai ke perumahan warga hingga

\section{Tinjauan Pustaka}

\section{$2.1 \quad$ Angin}

Untuk keperluan peramalan gelombang biasanya dipergunakan kecepatan angin pada ketinggian $10 \mathrm{~m}$. Apabila kecepatan tidak diukur pada ketinggian tersebut maka kecepatan angin perlu dikoreksi dengan rumus.

$$
\mathrm{U}(10)=\mathrm{U}(\mathrm{y})(10 / \mathrm{y})^{\wedge}(1 / 7)
$$

Apabila data kecepatan angin disuatu perairan memerlukan penyesuaian atau koreksi terhadap elevasi, koreksi stabilitas dan efeklokasi, maka dapat digunakan persamaan:

$\mathrm{U} \quad=\mathrm{RT} \times \mathrm{RL} \times \mathrm{U}$

Setelah dilakukan berbagai konversi kecepatan angin seperti yang dijelaskan di atas, kecepatan angin dikonversikan pada faktor tegangan angin dengan menggunakan rumus berikut :

$\mathrm{UA} \quad=0,71(\mathrm{UW}) 1,23$

\section{$2.2 \quad$ Fetch}

Saputro, dkk. (2010) berpendapat bahwa fetch adalah panjang keseluruhan suatu daerah https://doi.org/10.37598/tameh.v10i1.129 terjadi banjir rob. Upaya yang dapat diterapkan untuk mengurangi permasalahan abrasi di wilayah tersebut adalah dengan membangun konstruksi breakwater.

Penyebab abrasi itu sendiri dipicu oleh beberapa faktor seperti pasang surut air laut, gelombang laut yang tinggi dan arus laut yang berpotensi menimbulkan kerusakan sebagai akibat dari angin yang kencang sehingga menghasilkan gelombang yang merusak. Masyarakat juga menerima dampak abrasi tersebut yaitu pendapatan menurun, tempat tinggal tergenang oleh air laut dan mempengaruhi penurunan kualitas hidup masyarakat. Manfaat yang didapatkan dari penelitian ini berupa, untuk melindungi daerah pesisir pantai dan mencegah terjadinya gelombang tinggi yang masuk ke area warga dan salah satu upaya yang dapat diterapkan untuk mengurangi permasalahan abrasi di wilayah tersebut adalah dengan membangun konstruksi breakwater. Ruang lingkup penelitian ini dibatasi hanya meninjau tentang abrasi dan perencanaan bangunan pelindung pantai yang aman terhadap gelombang.

pembangkitan gelombang dimana angin berhembus dengan arah dan kecepatan yang konstan. Fetch dibatasi oleh daratan yang mengelilingi laut.

$F_{\text {eff }}=\frac{\sum x i \cos a}{\sum \cos a}$

\subsection{Gelombang}

Mamotodkk, (2013) berpendapat, gelombang di laut bisa bangkitkan oleh gelombang angin, gaya tarik matahari dan bulan (pasang surut), letusan gunung berapi atau gempa di laut (tsunami), dan lain sebagainya.

Berdasarkan data factor tegangan angin (UA), panjang fetch $\left(\mathrm{F}_{\text {eff }}\right)$, dan durasi maka dapat dilakukan peramalan gelombang dengan menggunakan grafik peramalan gelombang sehingga didapat tinggi dan periode gelombang signifikan.

Tinggi gelombang di laut terjadi akibat pengaruh refraksi gelombang diberikan oleh rumus berikut:

$\mathrm{H}_{0}=\mathrm{Ks} \cdot \mathrm{Kr} \cdot \mathrm{Ht}$

$\mathrm{Kr}=\sqrt{\frac{\cos \alpha_{\circ}}{\cos \alpha}}$ 


\subsection{Pasang Surut}

Wijaya dan Suntoyo (2013) berpendapat, pasang surut adalah fluktuasi muka air laut akibat adanya gaya tarik benda-benda langit, terutama matahari dan bulan terhadap massa air laut di bumi.Besar wave set-up dan run up gelombang laut diberikan oleh persamaan:

$$
\begin{aligned}
\mathrm{S}_{\mathrm{w}} & =0,19\left|1-2,82 \sqrt{\frac{\overline{H b}}{g T^{2}}}\right| \mathrm{H}_{\mathrm{b}} \\
\text { Lo } & =1,56 \times \mathrm{T}^{2} \\
\text { Ir } & =\frac{t g \theta}{\left(\frac{H}{\mathrm{Lo}}\right)^{0,5}}
\end{aligned}
$$

\subsection{Perhitungan Dimensi Bangunan}

Wijaya dan Suntoyo (2013) berpendapat, pasang surut adalah fluktuasi muka air laut akibat adanya gaya tarik benda-benda langit, terutama matahari dan bulan terhadap massa air laut di bumi,

Triatmodjo (2010) berpendapat, didalam perencanaan pemecah gelombang sisi miring, ditentukan berat butir batu pelindung, yang dapat dihitung menggunakan rumus Hudson.

$$
\begin{aligned}
\mathrm{W} & =\frac{\gamma r H^{3}}{K D S r-1^{3} \cos \theta} \\
\mathrm{Sr} & =\frac{\gamma r}{\gamma \alpha}
\end{aligned}
$$

Lebar puncak pemecah gelombang dapat dihitung dengan menggunakan persamaan berikut ini:

$$
B \quad=\mathrm{nK} \Delta\left[\frac{W}{\gamma r}\right]^{1 / 3}
$$

Tebal lapis pelindung dan jumlah butir batu tiap satuan luasan diberikan dalam rumus berikut:

$$
\begin{array}{ll}
\mathrm{t} & =\mathrm{nK} \Delta\left[\frac{W}{\gamma r}\right]^{1 / 3} \\
\mathrm{~N} & =A n K \Delta\left[1-\frac{P}{100}\right]\left[\frac{\gamma r}{W}\right] 2 / 3
\end{array}
$$

Berat butir batu untuk pondasi dan pelindung kaki (toe protection) dihitung dengan rumus berikut.

$$
\mathrm{W} \quad=\frac{\gamma r H^{3}}{N_{S}^{3} S_{r}-1}
$$

\section{MetodePenelitian}

\subsection{LokasiPenelitian}

Pesisir Pantai Gampong Jawa Lama, Kecamatan Banda Sakti, Lhokseumawe berjarak kira-kira $2 \mathrm{Km}$ dari Kota Lhokseumawe. Tepatnya pada posisi 5०11'02.5" Lintang Utara dan 97\%09'03.8" BujurTimur.Jarak lokasi Pantai GampongJawa Lama dari Banda Aceh kuranglebih $273 \mathrm{~km}$.

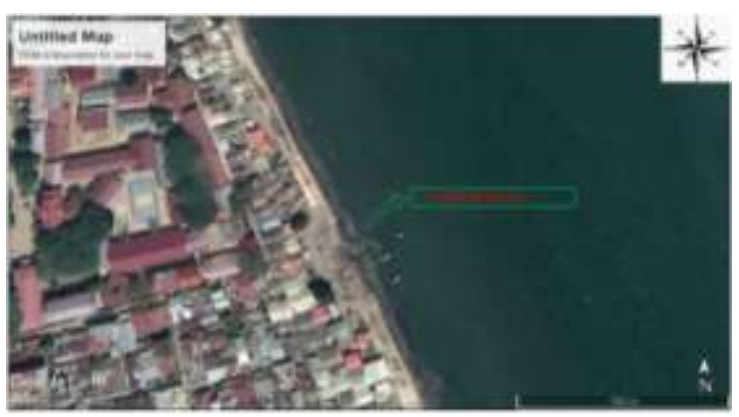

Gambar 1. Gambar Lokasi Penelitian

\subsection{Metode Pengumpulan Data}

\subsubsection{Data primer}

- Observasidan

- Dokumentasi lapangan

\subsubsection{Data sekunder}

- Pasang surut air laut, Data pasang surut diperoleh dari Badan Meteorologi Klimatologi dan Geofisika (BMKG) Belawan tahun 2020.

- Data angin, Data angin yang digunakan dalam perencanaan ini yaitu data angin 5 tahun terakhir. Data angin tersebut diambil dari Badan Meteorologi Klimatologi dan Geofisika Indrapuri, Kabupaten Aceh Besar tahun 2015 sampai dengan tahun 2019.

\section{Hasil dan Pembahasan}

\subsection{Analisis Arah dan KecepatanAngin}

Data angin yang digunakan selama 5 (lima) tahun yaitu dari tahun 2015 sampai tahun 
2019 dikelompokkan berdasarkan kecepatan dan arahnya kemudian ditabelkan persentasenya. Selanjutnya digambar sebagai mawar angin. Windrose tahunan umumnya frekuensi angin banyak berhembus dari arah "SW" (barat daya) dengan frekuensi kecepatan angin antara 4-6 Knots dengan jumlah total $58,33 \%$. Untuk menghitung panjang fetch arah angin dominan yang digunakan berada pada arah Timur Laut, karena arah Timur Laut panjang fetch nya yang bukan terkena daratan melainkan tertuju kepada pulau terdekat dengan persentase $10 \%$.

Setelah kita mengetahui kecepatan dominan dan arah angin dominan di lokasi perencanaan maka selanjutnya kita lanjutkan ke perhitungan kecepatan angin terkoreksi. Hasil kecepatan angin terkoreksi $(U)=7,72 \mathrm{~m} /$ det. Setelah selesai dikoreksi terhadap faktor tersebut, maka selanjutnya dapat menghitung koreksi tegangan angin, $U A=8,77 \mathrm{~m} / \mathrm{dt}$. Koreksi tegangan angin UA akan dipergunakan dalam peramalan gelombang.

Sesuai dengan arah dominan angin dan gelombang, maka untuk perhitungan fetch manggunakan arah Timur Laut. Berikut merupakan penggambaran panjang fetch :

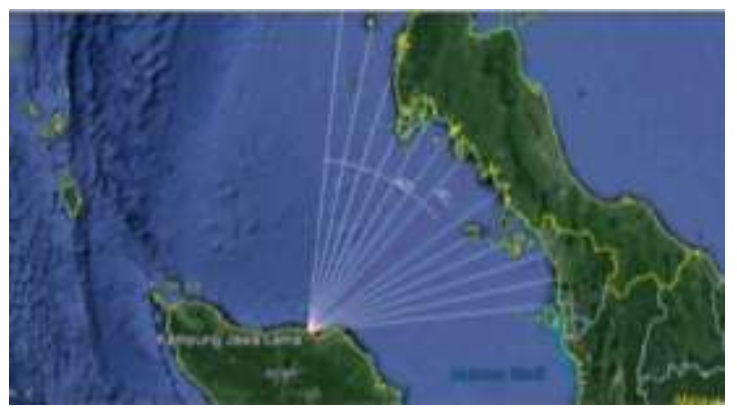

Gambar2. Fetch kota Lhokseumawe

Panjang garis fetch dihitung dari lokasi peramalan sampai kedaratan di ujung-ujung pulau yang membatasi. Hasil perhitungan panjang garis fetch rerata efektif (Feff) = $82,784 \mathrm{~km}$.

\subsection{Tinggi dan Periode Gelombang}

Tinggi dan periode gelombang didapat menggunakan angin terkoreksi $\left(\mathrm{U}_{\mathrm{A}}\right)$ dan fetch rerata efektif adalah $(\mathrm{Hs})=1,28 \mathrm{~m} / \mathrm{s}$ dan $(\mathrm{Ts})=$
5,58 detik. Perhitungan panjang gelombang di laut dalam $\left(L_{0}\right)=48,61 \mathrm{~m}$ dan kecepatan rambat gelombang di laut dalam $\left(\mathrm{C}_{0}\right)=8,71$ $\mathrm{m} /$ det. Tinggi gelombang rencana diperoleh $(H)=1,369 \mathrm{~m}$.

\subsection{Analisa Gelombang Pecah}

Dalam analisis gelombang pecah nilai $\left(\mathrm{H}_{0}^{\prime}\right)=$ 1,292 $\mathrm{m}$ dan tinggi gelombang ekivalen pada kedalaman $2 \mathrm{~m}$ diperoleh $\left(\frac{H_{O}}{g T^{2}}\right)=0,0042$, diperoleh tinggi gelombang pecah $(\mathrm{Hb})=1,679$ $\mathrm{m}$ dan kedalaman gelombang pecah $(\mathrm{db})=$ $1,880 \mathrm{~m}$.

\subsection{Pasang Surut dan Run Up Gelombang}

Berdasarkan data sekunder pasang surut dan konstanta - konstanta pasang surut maka di peroleh; elevasi muka air tertinggi $(H W L)= \pm$ 2,10 $\mathrm{m}$, elevasi tinggi muka air rata - rata $(\mathrm{MSL})= \pm 1,60 \mathrm{~m}$, danelevasi tinggimuka air terendah $(\mathrm{LWL})= \pm 0,00 \mathrm{~m}$. Selanjutnya dilakukan perhitungan kenaikan muka air akibat gelombang (wave set up).

Didapat nilai $(\mathrm{Sw})=0,252 \mathrm{~m}$. Dalam perencanaan ini kemiringan bangunan yang direncanakan adalah 1:2, sehingga di dapat tinggi Run uplr $=2,97$. Berdasarkan nilai grafik Gambar C.6 pada Lampiran C halaman 68 didapat nilai $\frac{R u}{H} g$ elombang, sehingga dapat dihitung nilai run up untuk bangunan pemecah gelombang dari bahan batu pecah $R u=1,574$.

\subsection{Dimensi Bangunan}

Pada perencanaan diperlukan menghitung ukuran dimensi bangunan breakwater yang sesuai danaman. Elevasi muka air rencana ditetapkan tinggi kebebasan $1 \mathrm{~m}$ sehingga elevasi puncak didapat $=5,574 \mathrm{~m}$, berat butir lapis lindung berupa batu besar dengan berat batu lapis lindung $1 \mathrm{~W}=0,321$ ton, lapisan 2 $\mathrm{W} / 10=0,032$ ton, tebal lapis dinding pengaman $\mathrm{t} 1=1,2 \mathrm{~m}, \mathrm{t} 2=0,6 \mathrm{~m}$, jumlah batu lapis dinding pengaman untuk satu satuan luas (10 m2) adalah 59 buah, lebar puncak 
bangunan $\mathrm{B}=1,2 \mathrm{~m}$. Pengaman kaki bangunan (Toe protection) terdiri dari lebar pelindung kaki $=1,8 \mathrm{~m}$, tebal pelindung kaki $\mathrm{t} 3$ $=1 \mathrm{~m}$ dengan berat batu pelindung $\mathrm{W} / 2=$ 0,160 ton

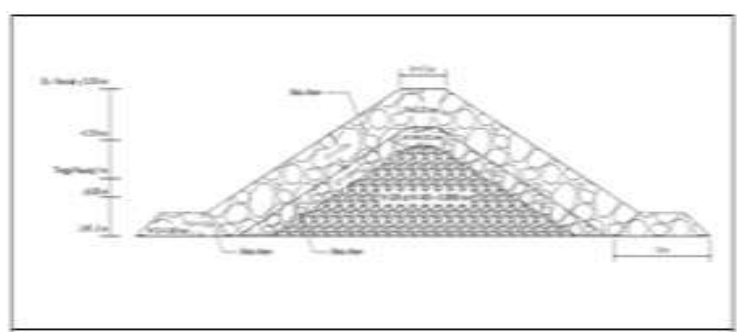

Gambar 3. Perencanaan dimensi bangunan breakwater

Berdasarkan hasil penelitianTinggi bangunan yang ada sebelumnya pada Pesisir Kampung Jawa Lama adalah 1,5 $\mathrm{m}$ dan lebar puncak 1 $\mathrm{m}$. Dengan menambah tinggi jagaan bangunan, maka pertambahan tinggi bangunan 4,074 $\mathrm{m}$ adalah $5,574 \mathrm{~m}$ dengan lebar puncak yang ada $1 \mathrm{~m}$ sehingga pertambahan $0,20 \mathrm{~m}$ adalah $1,2 \mathrm{~m}$, tebal lapis lindung pertama $1,2 \mathrm{~m}$ dan tebal lapis lindung kedua $0,60 \mathrm{~m}$. Lebar pelindung kaki $1,8 \mathrm{~m}$ dengan ketebalan $0,5 \mathrm{~m}$.

\section{Kesimpulan}

1. Berdasarkan perhitungan distribusi arah datang angin, frekuensi angin banyak berhembus dari arah barat daya dengan persentase 58,33 \%. Untuk menghitung panjang fetch arah angin dominan yang digunakan berada pada arah Timur Laut, karena arah Timur Laut panjang fetch nya yang bukan terkena daratan melainkan tertuju kepada pulau terdekat dengan persentase $10 \%$ dengan kecepa/tan angin elevasi pada $10 \mathrm{~m}$ adalah 5,40 $\mathrm{m} / \mathrm{dt}$.

2. Data angin ini digunakan dalam peramalan gelombang. Dari grafik peramalan gelombang tersebut didapatkan tinggi gelombang maksimum 1,28 meter dengan periode 5,58 detik. Berdasarkan dari perhitungan, tinggi bangunan pemecah gelombang adalah $5,574 \mathrm{~m}$ dengan lebar puncak $1,2 \mathrm{~m}$, tebal lapis lindung pertama $1,2 \mathrm{~m}$ dan tebal lapis lindung kedua $0,60 \mathrm{~m}$. Lebar pelindung kaki 1,8 $\mathrm{m}$ dengan ketebalan $0,5 \mathrm{~m}$

\section{DaftarPustaka}

[1] Christina, J., dan Putuhena, M, V. 2009. Stability Evaluation of Sea Wall Construction at Erie Village Location Nusaniwe District Amboina City. JurnalTeknologi. Vol.6, No.2. UKIM. Ambon.

[2] Cut Tia Farhadina (2019) "Analisa Bangunan Pelindung Reklamasi di Pantai Lhokseudu Kabupaten Aceh Besar". Repository Universitas Muhammadiyah Aceh

[3] Diposaptono,S 2000, Tsunami History And Database In Indonesia, Third Multi Lateral Wirkshop On Development Of Earthquake And Tsunami Disaster Mitigation Technologie And Their Integration For The Asia-Pacific Region, Earthquake Disaster Mitigation Research Center (Edm), Riken And Philippine Institute Of Vulcanology And Sesmology, Manila

[4] Fajar. 2012 .Mencegah dan Mengatasi Abrasi di Indonesia , pedemunegeri.com. Diunduh pada 9 Agustus 2013.

[5] Hariyoni.,Sisinggih, D., dan Marsudi, S. 2010. Studi Perencanaan Bangunan Pengendalian Akresi dan Abrasi di Pantai Tanjungwangi Kabupaten Banyuwangi. Jurnal Teknik Pengairan, Universitas Brawijaya, Malang.

[6] Hidayat, N. 2006. Konstruksi Bangunan Laut dan Pantai sebagai Alternatif Perlindungan Konstruksi Bangunan Laut dan Pantai sebagai Alternatif Perlindungan Daerah Pantai. Jurnal SMARTek. Vol.4. No.1. UniversitasTadulako, Palu.

[7] Mamoto, J, D., Jasin, M, I., dan Tawas, H, J. 2013. Perencanaan Jetty di Muara Sungai Ranoyapo Amorang. Jurnal Sipil Statik. Vol.1. No.6. Universitas Sam Ratulangi, Manado.

[8] Refi, A. 2013. Analisis Breakwater Pelabuhan Teluk Bayur dengan Menggunakan Batu Alam, Tetrapod, dan A-Jack. Jurnal Momentum, Volume 15. No. 2. InstitutTeknologi Padang.

[9] Restu Wigati, Bambang Adhi Priyambodhodan Shandilrfani Sasmita (2018) Perencanaan Pemecah Gelombang (Breakwater) Sisi Miring Di Pelabuhan Merak Dengan Menggunakan Batu Pecah dan Tetrapod.

[10] Saputro, M.S. danNawawi, M. 2010.,Analisis Abrasi Pantai Semarang Bagian Barat, Tugas akhir, Jurusan Teknik Sipil, Universitas Diponegoro, Semarang.

[11] Soehedy. 2011. Analisis Kecepatan Angin Terhadap Panjang Pemecah Gelombang (Breakwater) Pada Alur Pelabuhan Pulau Baai Bengkulu, Skripsi Jurusan Teknik Sipil Universitas Bengkulu. Bengkulu.

[12] Triatmodjo, B., 1999, Teknik Pantai, Beta Offset, Yogyakarta.

[13] Triatmodjo, B. 2010. Perencanaan Bangunan Pantai. Beta Offset, Yogyakarta.

[14] Ukkas, Marzuki, 2009, Studi Abrasi dan Sedimentasi di Perairan BUA Passimarannu Kecamatan Sinjai Timur Kabupaten Sinjai, Jurnal Sumberdaya Perairan

[15] Wijaya, H. G., danSuntoyo, W. 2013. Studi Perlindugan Pipeline PT. Pertamina Gas di Pesisir Indramayu, Jurnal Teknik Pomits. Vol.2. No.2. Institut Teknologi Sepuluh Nopember.

[16] Wisnu, 2002, Bangunan Pelindung Pantai, Yogyakarta.

[17] Zendrato, N.L.H., Terunajaya. 2015. Analisis Efektivitas Penggunaan Breakwater dengan Lapis Pelindung Bambu dan Tetrapod untuk Mereduksi Energi Gelombang Laut di Pelabuhan Kuala Tanjung. Jurnal Teknik Sipil. Universitas Sumatera Utara, Medan 